\title{
Effect of Holding Potential on the Dynamics of Homosynaptic Facilitation
}

\author{
Colin G. Evans, ${ }^{1,2}$ Bjoern Ch. Ludwar, ${ }^{1}$ Jordana Askanas, ${ }^{1}$ and Elizabeth C. Cropper ${ }^{1}$ \\ ${ }^{1}$ Fishberg Department of Neuroscience and Friedman Brain Institute, Mount Sinai School of Medicine, New York, New York 10029, ${ }^{2}$ Phase Five \\ Communications, New York, New York 10011
}

We study a form of short-term synaptic plasticity that was originally described as a graded potentiating effect of holding potential on spike-mediated synaptic transmission (Shimahara and Tauc, 1975). This form of plasticity has recently generated considerable interest, as it has become apparent that it is present in the mammalian brain (Clark and Häusser, 2006; Marder, 2006). It has been suggested that it adds a previously unappreciated analog component to spike-mediated synaptic transmission (Alle and Geiger, 2006, 2008). A limitation of most previous research in this area is that effects of holding potential have been studied in relative isolation. Presynaptic neurons are stimulated at low frequencies so that a second form of plasticity (homosynaptic facilitation) is not induced. Under physiological conditions, however, both forms of plasticity are likely to be coinduced. In this report, we study the two types of plasticity together in an experimentally advantageous preparation (the mollusk Aplysia californica). Somewhat surprisingly, we find that effects of holding potential can be relatively modest when presynaptic neurons are activated at low frequencies. Interestingly, however, changes in membrane potential are highly effective when homosynaptic facilitation is induced. In this situation, PSPs facilitate at an increased rate. To summarize, our research suggests a novel view of the effect of holding potential on synaptic transmission. We propose that, under physiological conditions, it modifies the dynamics of homosynaptic facilitation.

\section{Introduction}

At some synapses, transmitter release normally occurs with a low probability. There are, however, multiple forms of plasticity that can up-modulate transmission. The most well characterized form of short-term plasticity is homosynaptic facilitation, i.e., repeated presynaptic stimulation induces a progressive increase in PSP amplitude (Byrne and Kandel, 1996; Zucker and Regehr, 2002). This type of plasticity presumably serves a filtering function in that only repeated presynaptic activation evokes a postsynaptic action potential and response (Lisman, 1997; Dittman et al., 2000; Fortune and Rose, 2002). Additionally, synaptic transmission can be modified by potentiating effects of presynaptic membrane potential (Fig. 1). PSP amplitude is increased when the holding potential of the presynaptic neuron is more depolarized (even when firing frequency is constant). Although the latter plasticity was described almost 30 years ago in invertebrates (Shimahara and Tauc, 1975; Nicholls and Wallace, 1978), it has received renewed attention as a consequence of its identification in the mammalian brain (Awatramani et al., 2005; Alle and Geiger, 2006, 2008; Clark and Häusser, 2006; Marder, 2006; Shu et

\footnotetext{
Received May 11, 2011; revised June 6, 2011; accepted June 9, 2011.

Author contributions: E.C.C. designed research; C.G.E., B.Ch.L., and E.C.C. performed research; B.Ch.L., J.A., and E.C.C. analyzed data; E.C.C. wrote the paper.

This work was supported by a PHS Grant (MH51393). Some of the Aplysia used in this study were provided by the National Resource for Aplysia of the University of Miami under Grant RR10294 from the National Center for Research Resources, NIH. We thank K. R. Weiss for valuable comments on an earlier version of this manuscript.

Correspondence should be addressed to Elizabeth Cropper, Box 1065, Department of Neuroscience, Mt. Sinai School of Medicine, One Gustave L. Levy Place, New York, NY 10029. E-mail: elizabeth.cropper@gmail.com. DOI:10.1523/JNEUROSCI.2361-11.2011

Copyright $\odot 2011$ the authors $\quad 0270-6474 / 11 / 3111039-05 \$ 15.00 / 0$
}

al., 2006). In mammals, it may regulate synaptic transmission in a phasic manner [e.g., potentiate it during theta oscillations (Alle and Geiger, 2006)]. Interestingly, both facilitation and effects of holding potential can be present at the same synapse (Alle and Geiger, 2006). This raises a question: how will the two forms of plasticity interact?

We address this question in a well characterized preparation in Aplysia, at an excitatory synapse between a sensory neuron (B21) and a motor neuron (B8). B21 and B8 are neurons that constitute a reflex that closes the organ used to grasp food (the radula) (Rosen et al., 2000a,b). If B21 is peripherally activated at its resting membrane potential, however, it does not excite B8. Instead, motor programs are necessary to gate-in afferent activity (Evans et al., 2003). Motor programs are essentially two phases (Cropper et al., 2004). Initially, the radula protracts to grasp food. Subsequently, it retracts to pull food into the buccal cavity. Gating-in of afferent activity is phase-dependent. During ingestion, B21 excites B8 during retraction so that the radula closes as it moves backwards and pulls food in. To summarize, short-term potentiation of B21-B8 synaptic transmission is necessary for phase-dependent regulation of B21-B8 transmission during feeding.

During retraction (when sensorimotor transmission should occur), B21 is centrally depolarized (Rosen et al., 2000a; Evans et al., 2003). This depolarization is important for the required phase-dependent regulation of afferent transmission (Evans et al., 2003). Additionally, homosynaptic facilitation has been reported at the B21-B8 synapse, but not characterized (Rosen et al., $2000 \mathrm{~b}$ ). Here, we compare effects of holding potential and repeated activation of B21 on PSP amplitude. Interestingly, we find 
that changes in holding potential on their own are relatively ineffective at potentiating synaptic transmission. They do, however, significantly modify the rate of induction of facilitation. Our results identify a previously unreported effect of holding potential on synaptic transmission (modification of the dynamics of shortterm facilitation). This arrangement permits phase-dependent regulation of synaptic transmission without altering the filtering function of facilitating synapses.

\section{To increase PSP amplitude.....}

increase firing frequency

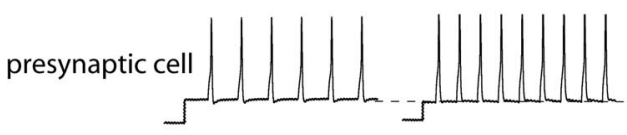

change the holding potential

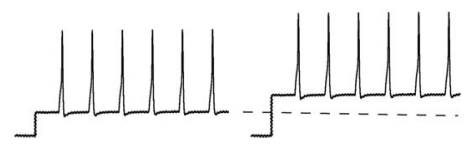

Figure 1. Two forms of short-term plasticity. PSP amplitude can be increased either by increasing the firing frequency of the presynaptic neuron (homosynaptic facilitation; left) or by changing the holding potential of the presynaptic neuron so that it is more depolarized (right).

\section{Materials and Methods}

Preparation. Experiments were conducted on Aplysia californica (200$400 \mathrm{~g}$ ), which are hermaphrodites. Animals were obtained from Marinus Scientific and maintained in tanks at $14-16^{\circ} \mathrm{C}$ for several days. They were anesthetized by injection of $\sim 100 \mathrm{ml}$ of isotonic $\mathrm{MgCl}_{2}$. The isolated buccal ganglion was removed from the animal and pinned in a Sylgard (Dow Corning) -lined dish. Experiments were conducted at $\sim 16^{\circ} \mathrm{C}$ in artificial seawater that had the following composition (in mM): $460 \mathrm{NaCl}$, $10 \mathrm{KCl}, 11 \mathrm{CaCl}_{2}, 55 \mathrm{MgCl}_{2}, 10$ HEPES, pH 7.6.

Electrophysiology. Up to four simultaneous intracellular recordings were amplified and displayed using Getting Model 5A amplifiers (Getting Instruments) modified for $100 \mathrm{nA}$ current injection, an AxoClamp 2B amplifier (Molecular Devices) in bridge mode, Tektronix AM 502 amplifiers, and a four-channel Tektronix storage oscilloscope (Model 5111). Data were digitized using a Digidata (Molecular Devices) and were acquired using Axoscope software (Molecular Devices).

To record from neurons, we used single-barrel electrodes fabricated from thin-walled glass capillary tubing filled with $3 \mathrm{~m} \mathrm{KAc}$ and $30 \mathrm{~mm}$ $\mathrm{KCl}$. Electrodes were beveled so that their impedances were $\sim 5-10 \mathrm{M} \Omega$. To induce spiking in B21, B21 was impaled with two electrodes, one for current injection and one for accurate monitoring of membrane potential. Spikes were evoked by injecting brief current pulses somatically. This triggers action potentials in B21's medial process (Evans et al., 2003). It is the lateral process, however, that is the primary point of contact with B8 (Borovikov et al., 2000). The somatic region of B21 must be centrally depolarized for spikes to propagate from the medial to the lateral process (Evans et al., 2003, 2007, 2008, 2011). Consequently, all experiments were performed at least $10 \mathrm{mV}$ above B21's normal resting potential $(-65 \mathrm{mV})$. In experiments where maximal effects of central depolarization were tested, the somatic region of $\mathrm{B} 21$ was $20 \mathrm{mV}$ above resting potential. This mimics the upper range of what is observed during ingestive feeding motor programs (Ludwar et al., 2009). In some experiments, we recorded from B8 under current-clamp conditions and monitored induced PSPs. In other experiments, we used a two-electrode voltage clamp to record induced PSCs.

Data analysis. Experiments were analyzed using either pClamp software (Molecular Devices) or Spike II (CED). Data are reported as means \pm SE; $n$ refers to the number of preparations. Statistical significance was determined as indicated in the text and was defined as $p<0.05$.

\section{Results}

Previous studies have demonstrated that there are graded effects of holding potential on B21-B8 synaptic transmission and that short-term facilitation is observed at this synapse (Rosen et al., 2000a,b; Ludwar et al., 2009). The relative efficacy of the two forms of plasticity has, however, not been evaluated. To accomplish this, we began by quantifying effects of repeated activation of B21 at physiologically relevant frequencies when the somatic region of the neuron was held at relatively hyperpolarized potentials $(-55 \mathrm{mV}$, which is $10 \mathrm{mV}$ above resting potential). The 10 $\mathrm{mV}$ depolarization was necessary to induce spike propagation to the output region of B21 (for further explanation, see Materials and Methods, above). Experiments were conducted under current-clamp conditions at lower frequencies $(2-6 \mathrm{~Hz})$. Voltage clamp was necessary to prevent spiking in B8 and temporal summation of PSCs at higher frequencies $(5-15 \mathrm{~Hz})$. At $+10 \mathrm{mV}$, the initial PSP (or PSC) was relatively small (Fig. $2 \mathrm{~A}$, circles). With repetitive activation of $\mathrm{B} 21$, however, facilitation was observed (Fig. $2 A)(n=$ at least 6$)$.

During feeding motor programs, B21 receives heterosynaptic input and its somatic membrane potential can be more depolarized than $-55 \mathrm{mV}$ (Rosen et al., 2000a; Ludwar et al., 2009). To study synaptic transmission at more depolarized potentials, we induced spiking at $6 \mathrm{~Hz}$ under current-clamp conditions and held B2 1 at $-45 \mathrm{mV}$ (20 mV above resting potential) (Fig. $2 \mathrm{~B}$ ). This is the upper range of the depolarization that is observed during a motor program. A question of interest was: will potentiating effects of holding potential occlude effects of repetitive activation?

Initial PSPs evoked at $+20 \mathrm{mV}$ were only $0.5 \pm 0.04 \mathrm{mV}$ (eight measurements from five animals) (Fig. $2 B$ ). This suggested that occlusion would not occur. Indeed, when we repetitively activated B21 and kept it depolarized, PSP amplitude increased to $5.3 \pm 0.21 \mathrm{mV}(p<0.001$ for the initial vs $6 \mathrm{~Hz}$ comparison $)$ (Fig. $2 B$ ). We hypothesized that this increase was due to the repetitive activation of $\mathrm{B} 21$ (and not due to a slowly developing effect of the change in membrane potential). Consistent with this idea, we maintained the $+20 \mathrm{mV}$ holding potential and decreased the stimulation frequency to $\sim 0.02 \mathrm{~Hz}$. PSP amplitude decreased to $0.9 \pm 0.1 \mathrm{mV}$ ( $p<0.0001$ for the 6 vs $0.02 \mathrm{~Hz}$ comparison) (Fig. $2 \mathrm{~B}$ ). Repeated stimulation at $6 \mathrm{~Hz}$ again increased PSP amplitude to $5.4 \pm 1.8 \mathrm{mV}$ ( $p<0.0001$ for the 0.02 vs second $6 \mathrm{~Hz}$ comparison) (Fig. $2 B$ ).

To more directly compare the efficacy of the two types of plasticity, we evaluated the effects of repetitive activation of B2 1 by plotting the initial versus steady-state amplitude of PSCs evoked at $10 \mathrm{mV}$ above resting potential when B21 was stimulated at 5 and $10 \mathrm{~Hz}$. We compared these PSCs to those induced at $20 \mathrm{mV}$ above resting potential without repetitive activation of B21 (Fig. 2C). Further, we computed differences between initial $+10 \mathrm{mV}$ values and all three other conditions $(+10 \mathrm{mV} / 5 \mathrm{~Hz},+10 \mathrm{mV} / 10 \mathrm{~Hz}$, and $+20 \mathrm{mV}$ ) (Fig. $2 \mathrm{D}$ ). The $+10 \mathrm{mV} / 10 \mathrm{~Hz}$ value was significantly larger than the $+20 \mathrm{mV}$ value but the $+10 \mathrm{mV} / 5 \mathrm{~Hz}$ value was not $(n=5$; overall ANOVA: $p=0.002 ; p=0.002$ for $10 \mathrm{~Hz}$ $\mathrm{vs}+20 \mathrm{mV}, p=0.4$ for $5 \mathrm{~Hz} \mathrm{vs}+20 \mathrm{mV}$, and $p=0.02$ for $5 \mathrm{~Hz}$ vs $10 \mathrm{~Hz}$ ). Together, these data indicate that membrane potential on its own is relatively ineffective at potentiating synaptic transmission. Although it can produce a twofold or threefold increase in amplitude, PSPs and PSCs are small to begin with. Consequently, alterations of this magnitude do not produce large postsynaptic responses. In contrast, PSP amplitude can be more effectively increased with repetitive activation of B21 (if the firing frequency is sufficiently high). 

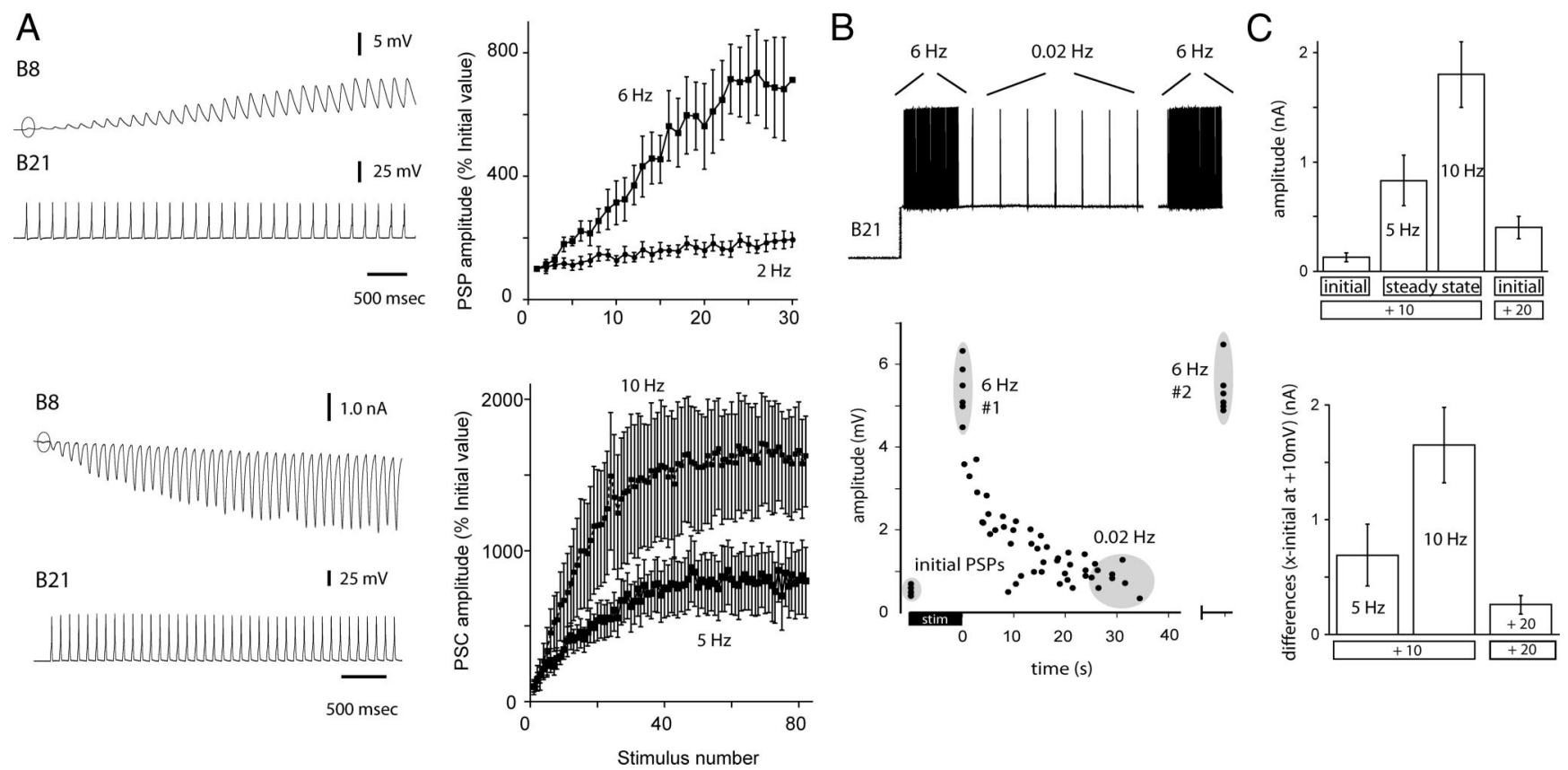

Stimulus number

Figure 2. A, Homosynaptic facilitation at the B21-B8 synapse with postsynaptic responses monitored under current clamp (top) and voltage clamp (bottom). The presynaptic membrane potential is $10 \mathrm{mV}$ above resting potential. Left, Raw data showing that PSPs and PSCs are initially very small (circles in B8 traces). With repetitive activation, amplitude increases. Right, Group data. $B$, Facilitation at $+20 \mathrm{mV}$. Top, Paradigm for a sample experiment. Bottom, Data from five preparations. Each dot is data from an individual experiment. The B21 membrane potential was stepped to $20 \mathrm{mV}$ above rest, and B21 was stimulated so that it fired at $6 \mathrm{~Hz}$ for $10 \mathrm{~s}$. Plotted are the amplitudes of the initial PSPs (first gray circle) and the amplitude of PSPs at the end of the $6 \mathrm{~Hz}$ stimulation (gray circle labeled $6 \mathrm{~Hz} \# 1$ ). With a variable delay, we then decreased the stimulation frequency to $0.02 \mathrm{~Hz}$ and plotted PSP amplitudes. Amplitude progressively decreased. The mean value reported in the text was determined using measurements taken after $\sim 30 \mathrm{~s}$ of $0.02 \mathrm{~Hz}$ stimulation (gray circle labeled $0.02 \mathrm{~Hz}$ ). Subsequent stimulation for $10 \mathrm{~s}$ at $6 \mathrm{~Hz}$ again increased PSP amplitude (gray circle labeled second $6 \mathrm{~Hz} \# 2$ ). C, Effects of membrane potential versus repetitive activation. Data from voltage-clamp experiments. Top, The first three bars are $+10 \mathrm{mV}$ data and show effects of repetitive activation. The initial PSC is very small (first bar). With repetitive activation, PSC amplitude is increased (second and third bars; steady-state amplitude reached at each frequency). The fourth bar illustrates the effect of changing holding potential (i.e., PSC induction at $+20 \mathrm{mV}$ without repetitive activation of B21). Bottom, Differences between PSCs induced under the three conditions (steady-state $5 \mathrm{~Hz}$, steady-state $10 \mathrm{~Hz}$, and $+20 \mathrm{mV}$ ) and the initial PSC induced at $+10 \mathrm{mV}$. The change in membrane potential alone is relatively ineffective at potentiating transmission.

It is interesting to note that at $10 \mathrm{mV}$ above resting potential, progressive increases in PSP amplitude induced by repetitive activation of B21 develop relatively slowly. This is particularly true for lower frequencies (Fig. $2 \mathrm{~A}$, upper right, $2 \mathrm{~Hz}$ plot). Even with stimulation at $6 \mathrm{~Hz}$, the mean PSP amplitude is increased to $3.2 \pm$ $1.1 \mathrm{mV}$, but this is after $5 \mathrm{~s}$ of stimulation $(n=6)$ (Fig. $2 A)$. The duration of the retraction phase of feeding motor programs is variable but can be as short as $3.5 \mathrm{~s}$ (Cropper et al., 1990).

We therefore addressed the question of whether changing holding potential could increase the rate at which facilitation develops. We plotted the amplitude of the first 20 PSPs evoked at +10 versus $+20 \mathrm{mV}$ for a range of frequencies (i.e., 2, 5, 10, and $15 \mathrm{~Hz}$ ). These plots were linear and the slope of the $+20 \mathrm{mV}$ plot was steeper than the slope of the $+10 \mathrm{mV}$ plot (Fig. $3 A 1, A 2$; Table 1). The biggest difference in slope was observed at the lowest frequency, i.e., $2 \mathrm{~Hz}$ (Table 1). The smallest difference was observed at the highest frequency, i.e., $15 \mathrm{~Hz}$. Since the rate at which facilitation was induced was altered by membrane potential, the steady-state values reached also differed for all frequencies tested, except $15 \mathrm{~Hz}(n=5 ; p<0.001$ for the comparisons at $2,4,5$, and $10 \mathrm{~Hz} ; p=0.06$ for the comparison at $15 \mathrm{~Hz}$ ) (Fig. $3 B$ ). Results of experiments with $15 \mathrm{~Hz}$ stimulation are apparently complicated by the development of synaptic depression $(n=5)$ (Fig. 3C).

A consequence of the effect of depolarization on the induction of facilitation is that the increase in amplitude observed with low-frequency stimulation at $+20 \mathrm{mV}$ resembles the increase observed with stimulation at twice the frequency at $+10 \mathrm{mV}$. For example, progressive increases in PSP amplitude observed when B21 was stimulated at $2 \mathrm{~Hz}$ and depolarized by $20 \mathrm{mV}$ were very similar to those observed when B21 was stimulated at $4 \mathrm{~Hz}$ but was held at $+10 \mathrm{mV}(n=5)$ (Fig. $3 A 1)$. This was also true when stimulation at $5 \mathrm{~Hz}$ at $+20 \mathrm{mV}$ was compared with stimulation at $10 \mathrm{~Hz}$ at $+10 \mathrm{mV}(n=5)$ (data not shown). These data indicate that membrane potential can alter the dynamics of facilitation by modifying its rate of induction.

\section{Discussion}

In this report, we study a molluscan synapse that is characterized by two forms of short-term synaptic plasticity: homosynaptic facilitation and potentiating effects of membrane potential on spike-mediated synaptic transmission. These two forms of plasticity are present together in other systems, including synapses in the mammalian brain (Alle and Geiger, 2006, 2008). To our knowledge, however, our work is the first that considers how these forms of plasticity interact under physiologically relevant conditions.

On its own, homosynaptic facilitation has been the subject of a great deal of prior research, and it has been suggested that it serves a filtering function (Lisman, 1997; Dittman et al., 2000; Fortune and Rose, 2002). When it is present, a single spike in a presynaptic neuron generally triggers a relatively small PSP, and spiking is not induced in the postsynaptic follower neuron. In contrast, when multiple action potentials are generated in the presynaptic neuron, PSPs become progressively larger and the postsynaptic cell is activated. In a sensorimotor context, filtering 

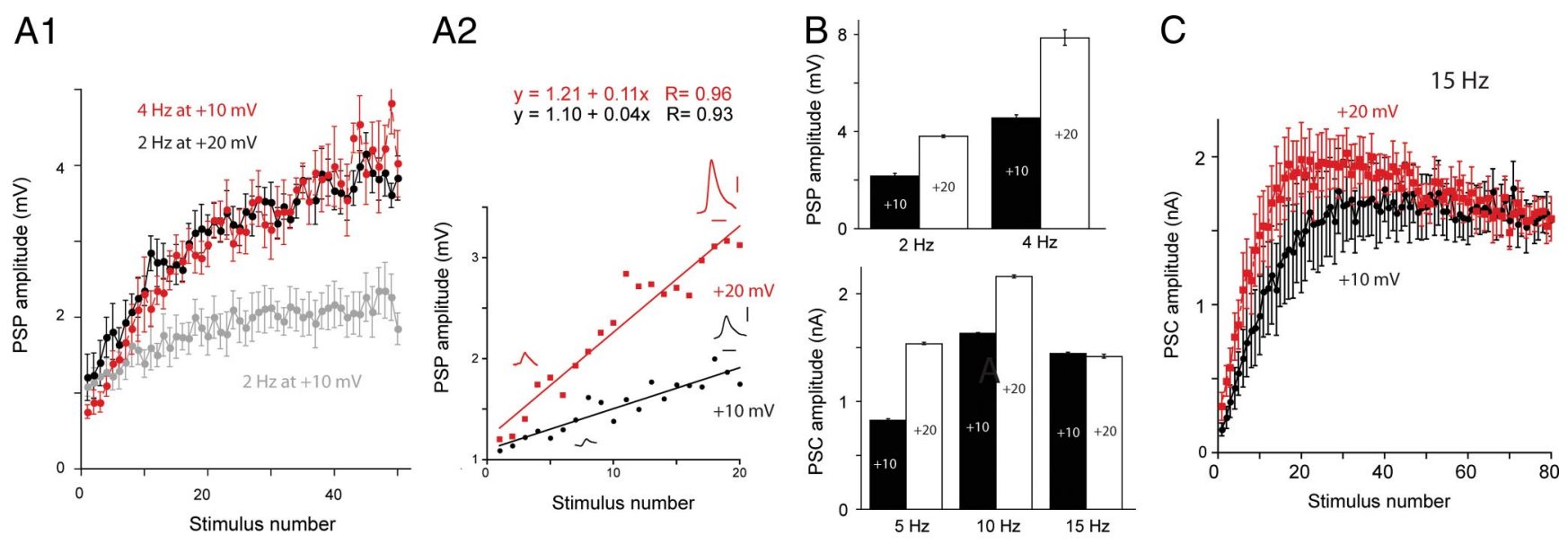

Figure 3. $\boldsymbol{A}$, Effect of membrane potential on the rate of induction of facilitation. $\boldsymbol{A}$, Plots of PSP amplitude with stimulation of B21 at $2 \mathrm{~Hz}$ at $+10 \mathrm{mV}$ (gray), $2 \mathrm{~Hz}$ at $+20 \mathrm{mV}$ (black), and $4 \mathrm{~Hz}$ at $+10 \mathrm{mV}$ (red). A2, Plots of the first 20 PSPs when B21 was stimulated at $2 \mathrm{~Hz}$ at $+10 \mathrm{mV}$ (black) and $2 \mathrm{~Hz}$ at $+20 \mathrm{mV}$ (red). PSPs shown are the first and twentieth PSP from a typical experiment under the two conditions. Plots are linear and the slope of the $+20 \mathrm{mV}$ plot is steeper than the slope of the $+10 \mathrm{mV}$ plot. Scale bars, $1 \mathrm{mV}$ and $50 \mathrm{~ms}$. $\boldsymbol{B}$, Effect of membrane potential on the steady-state amplitude of postsynaptic responses. PSP (top) and PSC (bottom) amplitudes under steady-state conditions at the indicated frequencies at $+10 \mathrm{mV}$ (black bars) versus $+20 \mathrm{mV}$ (white bars). Steady-state values were larger at $+20 \mathrm{mV}$ for all frequencies except for $15 \mathrm{~Hz}$. C, Effect of holding potential with stimulation at $15 \mathrm{~Hz}$. Plots of PSC amplitude when B21 was stimulated at 15 $\mathrm{Hz}$ at $+10 \mathrm{mV}$ (black) and $+20 \mathrm{mV}$ (red). Note the apparent depression, particularly at $+20 \mathrm{mV}$.

Table 1. Effect of membrane potential on the induction of facilitation at different frequencies

\begin{tabular}{lllll}
\hline Frequency & Membrane potential & $R$ value & Slope & Increase \\
\hline $2 \mathrm{~Hz}$ & $+10 \mathrm{mV}$ & 0.93 & 0.04 & \\
& $+20 \mathrm{mV}$ & 0.96 & 0.11 & $\times 2.8$ \\
$5 \mathrm{~Hz}$ & $+10 \mathrm{mV}$ & 0.96 & 0.02 & \\
& $+20 \mathrm{mV}$ & 0.98 & 0.05 & $\times 2.5$ \\
$10 \mathrm{~Hz}$ & $+10 \mathrm{mV}$ & 0.99 & 0.06 & \\
& $+20 \mathrm{mV}$ & 0.97 & 0.09 & $\times 1.5$ \\
$15 \mathrm{~Hz}$ & $+10 \mathrm{mV}$ & 0.98 & 0.07 & \\
& $+20 \mathrm{mV}$ & 0.97 & 0.09 & $\times 1.3$ \\
\hline
\end{tabular}

Values in the last three columns were calculated from the first 20 stimuli at the indicated frequency and membrane potential (Fig. 3A2). Plots of these data were linear and had the indicated slope. The last column is the ratio of the $+20 \mathrm{mV}$ slope/ $+10 \mathrm{mV}$ slope at the indicated frequency.

occurs in that there is no motor response to a single isolated stimulus. Repeated afferent activation is required to evoke a behavioral response.

Effects of holding potential on synaptic transmission have been less extensively investigated. They were originally described almost 30 years ago in invertebrate preparations (Shimahara and Tauc, 1975; Nicholls and Wallace, 1978). It was not until relatively recently, however, that it became apparent that this form of plasticity is present in mammals (Awatramani et al., 2005; Alle and Geiger, 2006, 2008; Clark and Häusser, 2006; Marder, 2006; Shu et al., 2006). Further, interest in this phenomenon in the mammalian brain has been sparked by measurements of axonal length constants, which can be surprisingly long (Alle and Geiger, 2006; Shu et al., 2006). Consequently, it has become apparent that somatic and dendritic events can modify axonal release in mammalian cells. For example, subthreshold depolarizations that mimic synchronous oscillatory activity can phasically potentiate spike-mediated synaptic transmission (Alle and Geiger, 2006). These findings are particularly exciting given the growing body of literature demonstrating the importance of oscillatory activity. For example, in the context of sensorimotor transmission, it has been suggested that oscillatory activity may serve as a basis for selective attention (Niebur, 2002; Lakatos et al., 2008).

Although facilitation and effects of holding potential have been individually investigated in other preparations, there has been little consideration of the two forms of plasticity together. In hippocampal neurons, it has been demonstrated that occlusion does not occur; i.e., when presynaptic neurons are depolarized, PSPs are potentiated but homosynaptic facilitation is still observed (Alle and Geiger, 2006, 2008). In this report, we show that this is also true at the $\mathrm{B} 21-\mathrm{B} 8$ synaptic junction. Our experiments differ from previous work in that they go beyond this initial observation to specifically evaluate and compare the relative efficacy of the two forms of plasticity. In this discussion, we emphasize two findings of particular interest.

The first is that changes in membrane potential on their own are relatively ineffective at up-modulating synaptic transmission. Thus, with central depolarization, the amplitude of postsynaptic responses is increased. However, in absolute terms (millivolt or nanoampere), PSPs or PSCs are not large (e.g., PSPs are still generally $<1 \mathrm{mV}$ ). Consequently, they are relatively unlikely to induce a motor response. We suggest that an important physiological consequence of this arrangement is that it does not eliminate the filtering function of the synapse. It is likely that multiple presynaptic spikes will still be necessary to evoke a motor response.

Second, we show when B21 is repetitively activated at relatively hyperpolarized potentials (i.e., $+10 \mathrm{mV}$ ), although there can be more dramatic increases in PSP or PSC amplitude, potentiation can require relatively long periods of presynaptic stimulation. This is particularly true at low frequencies. For example, when $\mathrm{B} 21$ is stimulated at $2 \mathrm{~Hz}$ and is $10 \mathrm{mV}$ above resting potential, PSP amplitude can be increased to $\sim 2 \mathrm{mV}$. On average, however, this requires $\sim 10 \mathrm{~s}$ of stimulation. The duration of bursts of feeding activity vary, but in intact animals, the mean duration of retraction can be as short as $3.5 \mathrm{~s}$ during repetitive ingestion of food (Cropper et al., 1990). It is therefore interesting that changes in membrane potential increase the rate at which facilitation develops. For example, when B21 is stimulated at 2 $\mathrm{Hz}$, an increase in membrane depolarization from 10 to $20 \mathrm{mV}$ reduces the period of stimulation necessary to induce a $2 \mathrm{mV}$ PSP by more than half.

We suggest that the effect of membrane potential on the rate of induction of facilitation is important since, under physiological conditions, B21, like many other neurons, fires in a burst of a 
specified duration. This duration limits the time available for facilitation to develop, which in turn limits the potential efficacy of stimulation at a given frequency (particularly when the frequency is low). To summarize, with no effect of membrane potential, higher firing frequencies are necessary to achieve a certain level of potentiation. An effect of membrane potential on the rate of induction of facilitation may therefore be important for reducing the firing frequency requirements for a presynaptic neuron. In general, this may be an advantage at synapses such as B21-B8, where depression is developed with relatively high-frequency stimulation.

\section{References}

Alle H, Geiger JR (2006) Combined analog and action potential coding in hippocampal mossy fibers. Science 311:1290-1293.

Alle H, Geiger JR (2008) Analog signalling in mammalian cortical axons. Curr Opin Neurobiol 18:314-320.

Awatramani GB, Price GD, Trussell LO (2005) Modulation of transmitter release by presynaptic resting potential and background calcium levels. Neuron 48:109-121.

Borovikov D, Evans CG, Jing J, Rosen SC, Cropper EC (2000) A proprioceptive role for an exteroceptive mechanoafferent neuron in Aplysia. J Neurosci 20:1990-2002.

Byrne JH, Kandel ER (1996) Presynaptic facilitation revisited: state and time dependence. J Neurosci 16:425-435.

Clark B, Häusser M (2006) Neural coding: hybrid analog and digital signalling in axons. Curr Biol 16:R585-R588.

Cropper EC, Kupfermann I, Weiss KR (1990) Differential firing patterns of the peptide-containing cholinergic motor neurons B15 and B16 during feeding behavior in Aplysia. Brain Res 522:176-179.

Cropper EC, Evans CG, Hurwitz I, Jing J, Proekt A, Romero A, Rosen SC (2004) Feeding neural networks in the mollusc Aplysia. Neurosignals 13:70-86.

Dittman JS, Kreitzer AC, Regehr WG (2000) Interplay between facilitation, depression, and residual calcium at three presynaptic terminals. J Neurosci 20:1374-1385.

Evans CG, Jing J, Rosen SC, Cropper EC (2003) Regulation of spike initia- tion and propagation in an Aplysia sensory neuron: gating-in via central depolarization. J Neurosci 23:2920-2931.

Evans CG, Ludwar BCh, Cropper EC (2007) Mechanoafferent neuron with an inexcitable somatic region: consequences for the regulation of spike propagation and afferent transmission. J Neurophysiol 97:3126-3130.

Evans CG, Kang T, Cropper EC (2008) Selective spike propagation in the central processes of an invertebrate neuron. J Neurophysiol 100:2940-2947.

Evans CG, Ludwar BC, Kang T, Cropper EC (2011) Effect of presynaptic membrane potential on electrical vs chemical synaptic transmission. J Neurophysiol. Advance online publication. doi: 10.1152/jn.00340.2011.

Fortune ES, Rose GJ (2002) Roles for short-term synaptic plasticity in behavior. J Physiol Paris 96:539-545.

Lakatos P, Karmos G, Mehta AD, Ulbert I, Schroeder CE (2008) Entrainment of neuronal oscillations as a mechanism of attentional selection. Science 320:110-113.

Lisman JE (1997) Bursts as a unit of neural information: making unreliable synapses reliable. Trends Neurosci 20:38-43.

Ludwar BCh, Evans CG, Jing J, Cropper EC (2009) Two distinct mechanisms mediate potentiating effects of depolarization on synaptic transmission. J Neurophysiol 102:1976-1983.

Marder E (2006) Neurobiology: extending influence. Nature 441:702-703.

Nicholls J, Wallace BG (1978) Modulation of transmission at an inhibitory synapse in the central nervous system of the leech. J Physiol 281:157-170.

Niebur E (2002) Electrophysiological correlates of synchronous neural activity and attention: a short review. Biosystems 67:157-166.

Rosen SC, Miller MW, Cropper EC, Kupfermann I (2000a) Outputs of radula mechanoafferent neurons in Aplysia are modulated by motor neurons, interneurons, and sensory neurons. J Neurophysiol 83:1621-1636.

Rosen SC, Miller MW, Evans CG, Cropper EC, Kupfermann I (2000b) Diverse synaptic connections between peptidergic radula mechanoafferent neurons and neurons in the feeding system of Aplysia. J Neurophysiol 83:1605-1620.

Shimahara T, Tauc L (1975) Multiple interneuronal afferents to the giant cells in Aplysia. J Physiol 247:299-319.

Shu Y, Hasenstaub A, Duque A, Yu Y, McCormick DA (2006) Modulation of intracortical synaptic potentials by presynaptic somatic membrane potential. Nature 441:761-765.

Zucker RS, Regehr WG (2002) Short-term synaptic plasticity. Annual Rev Physiol 64:355-405. 